\title{
Temperature Effects on Resistance to Meloidogyne spp. in Excised Tomato Roots
}

\author{
Aref A. Abdul-Baki and Sanāa A. Haroon' ${ }^{1}$ \\ Vegetable Laboratory, Plant Sciences Institute, Agricultural Research Service, \\ U.S. Department of Agriculture, Beltsville, MD 20705
}

David J. Chitwood ${ }^{2}$

Nematology Laboratory, Plant Sciences Institute, Agricultural Research Service, U.S. Department of Agriculture, Beltsville, MD 20705

Additional index words. Lycopersicon esculentum, Meloidogyne incognita, Meloidogyne arenaria, root explant culture, nematode, resistance

\begin{abstract}
Resistance to root-knot nematodes (Meloidogyne spp.) in tomato (Lycopersicon esculentum Mill.) plants has been reported to break down at soil temperatures $>28 \mathrm{C}$. We evaluated in vitro root explants of tomato heterozygous (Mimi), homozygous (MiMi) at the Mi locus, or lacking the Mi-1 gene for resistance to Meloidogyne incognita (Kofoid \& White) Chitwood and Meloidogyne arenaria (Neal) Chitwood at 28, 31, 34, and 37C. Genotypes Ace-55 UF and Rutgers, lacking the dominant allele, were susceptible to $M$. incognita and $M$. arenaria at all temperatures. Genotypes possessing the dominant allele (heterozygous or homozygous) were equally resistant to both nematode species. The resistance level in these genotypes was maintained fully at $31 \mathrm{C}$, partially maintained at $34 \mathrm{C}$, and lost at 37C. Resistance in the heat-tolerant $M i$-heterozygous accession CLN 475$\mathrm{BC}_{1} \mathrm{~F}_{2}-$ 265-4-19 was not different from that of the heat-sensitive genotypes. As temperature increased, the genotypes differed in their sensitivity to resistance conferred by the $\mathrm{Mi}$ 1 locus.
\end{abstract}

Root-knot nematodes of the genus Meloidogyne (Kofoid and White) Chitwood are distributed more widely than any other genus of plant-parasitic nematodes (Sasser, 1977) and cause severe damage to a wide variety of crops (Eisenback and Triantaphyllou, 1991). In tropical, subtropical, and warm temperate areas, where temperatures are high and growing seasons are sufficiently long to allow the production of several nematode generations per year, nematode population densities increase rapidly (Cap et al., 1993) and crop yields may be drastically reduced (Lamberti, 1979).

Of 37 recognized species of root-knot nematodes, seven are known to attack tomatoes, and four inflict severe damage (Medina Filho and Stevens, 1980). In order of decreasing incidence, they are Meloidogyne incognita, $M$. arenaria, M. javanica (Treub) Chitwood, and M. hapla Chitwood (Mai, 1985). The traditional method of evaluating nematode resistance involves the direct observation of root galling developed by young plants grown in

Received for publication 20 Mar. 1995. Accepted for publication 28 Sept. 1995. We thank William Potts for statistical analysis of the data and Naeema Latif and Peter Ewashkow for technical assistance. The cost of publishing this paper was defrayed in part by the payment of page charges. Under postal regulations, this paper therefore must be hereby marked advertisement solely to indicate this fact.

${ }^{1}$ Visiting scientist from Nematology Dept., Univ. of Cairo, Cairo, Egypt.

${ }^{2}$ To whom reprint requests should be addressed. heavily infested soil (Medina Filho and Stevens, 1980).

Resistance in tomato to root-knot nematodes first was observed by Bailey (1941) in the wild species Lycopersicon peruvianum (L.) Mill. P.I. 128657. Using embryo rescue, Smith (1944) introduced this trait into the domesticated L. esculentum. This resistance was subsequently shown to be encoded by a single dominant gene $(\mathrm{Mi}-1)$ located on chromosome 6 (Ho et al., 1992). This gene confers resistance to $M$. incognita, $M$. arenaria, and $M$. javanica, but not M. hapla (Cap et al., 1993).

Many factors (e.g., heat, soil moisture, and host variety) affect the rate at which the life cycle of the nematode proceeds, ultimately regulating population increase (Ferris and Van Gundy, 1979). Temperature is the primary influence because it affects the metabolic and developmental rates of nematodes and the functioning of the $M i-1$ gene.

Homozygous dominant plants $(\mathrm{MiMi})$ are less susceptible to galling than heterozygous plants (Barham and Winstead, 1957; Laterrot, 1973), suggesting an additive gene action at the Mi locus. A breakdown in Mi-conferred resistance occurs when soil temperatures are 228C (Dropkin, 1969; Medina Filho and Stevens, 1980). At $\geq 28$ C, resistant and susceptible plants are affected equally (Dropkin, 1976). More recently, Ammati et al. (1985) and Cap et al. (1993) reported that heat-stable resistance in Lycopersicon is conditioned by $M i-2$, which is nonallelic to $M i-1$. The $M i-2$ locus confers resistance to the four major
Meloidogyne species, including M. hapla. However, this resistance has not been transferred into commercial L. esculentum cultivars yet.

At $28 \mathrm{C}$, the resistance conferred by the $\mathrm{Mi}$ 1 gene breaks down and marks the point above which tomato genotypes exhibit heat stress symptoms, reducing vigor and yield (AbdulBaki, 1991). Our study was designed to determine 1) the temperature at which resistance conferred by the $M i-1$ gene breaks down after inoculating tomato genotypes that have the $M i-1$ gene in homozygous or heterozygous form with $M$. incognita or $M$. arenaria and 2) whether the action of the $M i-1$ gene is altered by high temperature in a heat-tolerant tomato genotype.

\section{Materials and Methods}

Properties and sources of genotypes. Eight tomato genotypes were selected based on susceptibility or resistance to Meloidogyne spp. root-knot nematodes and on tolerance to hightemperature stress. Rutgers and Ace-55 UF lack the dominant allele at the $M i-1$ locus, PikRed, Pik-Rite, Better Boy, Celebrity, and CLN 475- $\mathrm{BC}_{1} \mathrm{~F}_{2}-265-4-19$ (CLN) are heterozygous (Mimi) at the Mi-1 locus, while Orion is homozygous (MiMi). All genotypes, except CLN, are heat sensitive. CLN seeds were made available through the Asian Vegetable Research and Development Center, Taiwan. Seeds of the remaining genotypes were provided by Harris Moran Seed Co., Modesto, Calif.

Root explant cultures and inoculation. Preparation of root explant cultures was accomplished according to Haroon et al. (1993). Seeds (300 per genotype) were sonicated for 3 min in $95 \%$ ethanol followed by a 10 -min soak in $0.5 \%$ sodium hypochlorite and were transferred to sterile $1.5 \%$ water agar plates where they were maintained for 3 days at $28 \mathrm{C}$. A 5$\mathrm{mm}$-long root tip was excised from each seedling and then was transferred to a sterile petri plate (one root tip per plate) containing Gamborg's B-5 medium (Gibco, Grand Island, N.Y.), resulting in a total of 60 petri plates for each tomato genotype. One-third (20 plates) of the petri plates was left uninoculated; one-third was inoculated with egg masses (one per plate) from cultures of $M$. incognita, race 3; and one-third was inoculated with egg masses (one per plate) from cultures of $M$. arenaria. The $M$. incognita and $M$. arenaria cultures had been maintained on sterile root explants of Rutgers tomato. Hence, the three main treatments in each of the eight tomato genotypes were uninoculated and inoculated with $M$. incognita or $M$. arenaria.

To determine the extent of resistance offered by the $M i-1$ gene against $M$. incognita and $M$. arenaria with temperatures at various heat stress levels $(28,31,34$, and 37C), the petri plates from each of the three main treatments ( 20 plates per genotype) were divided further into four groups, each consisting of five plates. Each of the four groups was placed in a plastic bag, sealed, and incubated at the constant temperatures noted and was evaluated after 35 days. One growth chamber was 
alloted for each temperature, resulting in 120 plates within each chamber. This entire experiment was performed twice.

To determine total increase in fresh mass of uninoculated excised roots at the end of 35 days, the petri plates were placed in a microwave oven for $20 \mathrm{sec}$ to melt the agar at $56 \mathrm{C}$. The roots were removed, blotted on filter paper to remove excess moisture, and weighed. To determine nematode penetration, all root explants that had been inoculated with $M$. incognita or $M$. arenaria were handled similarly and then stained with cotton blue, a modification from Bridge et al. (1981). Enumeration of the second-stage juveniles (J2) per root was made on a stereomicroscope. The two experiments were combined and analyzed as a split plot; temperature was the whole-plot treatment, the growth chambers were the whole plots, and the subplot treatments were arranged as an eight (genotype) $\times$ two (nematode species) factorial.

An index measuring nematode resistance was calculated similarly to Cap et al. (1991). Plants were considered resistant if the number of juveniles per gram of root was $<10 \%$ of the average of the corresponding number per gram for susceptible genotypes Ace-55 UF and Rutgers.

The percent resistance for the five plates for each genotype $\times$ species $\times$ temperature combination was used as the response variable. The split-plot analysis of variance model was fitted by weighted least squares to account for heterogeneous variance. For each temperature $\times$ species combination, the nematode resistance for each heterozygous strain was compared to that of the homozygous strain Orion using a $t$ test.

\section{Results}

Fresh mass of excised roots held at a constant 28C differed among genotypes (Table 1). CLN grew best and Rutgers least; Pik-Rite was least affected by an increase in temperature. In contrast, root growth of the other genotypes was significantly less at 31 and $34 \mathrm{C}$, with the reduction being most severe in

Table 1. Mean fresh root mass (milligram) per uninoculated excised root after 35 days.

\begin{tabular}{|c|c|c|c|c|}
\hline \multirow[b]{2}{*}{ Genotype } & \multicolumn{4}{|c|}{ Temp $\left({ }^{\circ} \mathrm{C}\right)$} \\
\hline & 28 & & & 37 \\
\hline Ace-55 UF & 470 & 260 & & \\
\hline & 30 & 160 & & \\
\hline & 80 & 440 & & \\
\hline & 10 & 530 & 500 & 240 \\
\hline & & 450 & 590 & \\
\hline & 570 & 560 & 560 & 300 \\
\hline & 790 & 510 & 580 & \\
\hline & 640 & 520 & 530 & \\
\hline \multicolumn{5}{|l|}{ Maximum $\operatorname{LSD}_{\mathrm{A}, 0.05}=80^{\mathrm{z}}$} \\
\hline \multicolumn{5}{|l|}{ Maximum $\operatorname{LSD}_{\mathrm{B}, 0.05}=100^{\mathrm{z}}$} \\
\hline \multicolumn{5}{|c|}{$\begin{array}{l}{ }^{2} \text { The maximum least significant difference is for } \\
\text { comparisons between genotypes within tempera- } \\
\text { tures ( } L S D_{A} \text { ) and corresponds to the maximum SE } \\
\text { among the pairwise differences. The maximum } L S D_{B} \\
\text { is for comparisons between temperatures within } \\
\text { genotypes and corresponds to the maximum } S E \\
\text { among the pairwise differences. }\end{array}$} \\
\hline
\end{tabular}

Rutgers. At 37C, root growth of all genotypes was severely affected. However, Pik-Rite consistently showed the lowest reduction in root growth among all genotypes, followed by $\mathrm{Ce}$ lebrity.

Growth reduction in heat-tolerant CLN was similar to that exhibited by some of the heat-sensitive genotypes. Likewise, the reduction in root growth by the $M i-1$ homozygous genotype Orion was similar to that in the heterozygous genotypes. Except for Ace-55 $\mathrm{UF}$ at $34 \mathrm{C}$, roots of $M i-1$ homozygous and heterozygous genotypes at 28,31 , and $34 \mathrm{C}$ generally grew more than those of Rutgers and Ace-55 UF, which lack the $M i-1$ gene. At 37C, growth was severely reduced in all genotypes, regardless of the presence of the $M i$-allele or heat tolerance.

Changes in the expression of resistance conferred by the $M i-1$ gene in tomato genotypes, in response to $M$. incognita and $M$. arenaria with increasing temperatures from 28 to $37 \mathrm{C}$, were determined on $\mathrm{J} 2$ nematodes (Table 2). All but Better Boy exhibited 100\% resistance to both nematode species at 28 and 31C; Better Boy demonstrated $91 \%$ resistance in the $\mathrm{J} 2$ stage of $M$. arenaria. Differences in the $M i-1$ gene expression among genotypes began to appear at 34C. Celebrity and Better Boy, which are Mimi, demonstrated the highest levels of resistance to $M$. incognita and $M$. arenaria. These levels were higher than the level of resistance expressed in Orion (MiMi).

\section{Discussion}

Our results indicate that the fresh mass of tomato genotype root explants in the presence of $M$. incognita and $M$. arenaria was adversely affected by high temperature in some, but not all, genotypes (e.g., Pik-Rite). Moreover, fresh mass did not seem to be related to heat tolerance (CLN) or the presence of the $M i-1$ gene. Except for Pik-Rite, root growth of all genotypes was reduced significantly $(\geq 36 \%)$ before loss of resistance to $M$. incognita and $M$. arenaria. This result suggests that resistance conferred by the $M i-1$ gene is expressed forms. Our results differ from those reported by Barham and Winstead (1957) and Laterrot (1973), in which tomato plants homozygous (MiMi) at the $M i-1$ locus were usually devoid equally in the homozygous and heterozygous

of galls after 5 to 7 weeks of exposure to infected soils, whereas heterozygous (Mimi) plants displayed galls more frequently.

Dropkin (1969) reported differences among tomato genotypes with respect to the temperature at which resistance conferred by the $M i-1$ gene is lost as the temperature increases. Research indicates that resistance is lost at $>28 \mathrm{C}$ (Papadopolous and Tiessen, 1983; Tindall et al., 1990). Our results suggest that resistance was maintained in all genotypes at $>34 \mathrm{C}$. The difference between our results and those reported by others may be attributable to differences in experimental approach. The in vitro method we used for growing the root explants in a growth chamber provides more precise control of the temperature than growing the intact plant in soil medium in the greenhouse. Moreover, the culture system was independent of factors such as the aerial portions of the intact plants, air temperature, and demand of sinks for synthates. As such, the results reflect the growth pattern of isolated roots in a confined environment, rather than the behavior of intact roots in a complex environment influenced by factors that affect growth (Papadopolous and Tiessen, 1983; Tindall et al., 1990). Furthermore, the culture system is less costly and more adapted to routine testing than growing the plants in infested soil in the greenhouse. Thus, routine evaluation of additional tomato germplasm for nematode resistance could be facilitated by adopting the root explant method.

\section{Literature Cited}

Abdul-Baki, A. 1991. Tolerance of tomato cultivars and selected germplasm to heat stress. J. Amer. Soc. Hort. Sci. 116:1113-1116.

Ammati, M., I.J. Thomason, and P.A. Roberts. 1985. Screening Lycopersicon species for new genes imparting resistance to root-knot nematodes (Meloidogyne spp.). Plant Dis. 69:112-115.

Bailey, D.M. 1941. The seedling method for rootknot nematode resistance. Proc. Amer. Soc. Hort. Sci. 38:573-575.

Barham, W.S. and N.N. Winstead. 1957. Inheritance of resistance to root-knot nematodes in tomatoes. Proc. Amer. Soc. Hort. Sci. 69:372377.

Bridge, J.S., L. Page, and S.M. Jordan. 1981. An improved method for staining nematodes in roots, p. 137. In: Rothamsted Report for 1981. Rothamsted Agr. Expt. Sta., Harpenden, U.K.

Table 2. Mean index of resistance ${ }^{z}$ by tomato genotypes to Meloidogyne incognita and M. arenaria incubated at different temperatures and evaluated for second-stage juvenile development after 35 days.

\begin{tabular}{|c|c|c|c|c|c|c|c|c|c|}
\hline \multirow[b]{3}{*}{ Genotype } & \multirow{3}{*}{$\begin{array}{l}\text { Genotype } \\
M i-1 \text { locus }\end{array}$} & \multicolumn{4}{|c|}{ M. incognita } & \multicolumn{4}{|c|}{ M. arenaria } \\
\hline & & \multicolumn{4}{|c|}{ Temp $\left({ }^{\circ} \mathrm{C}\right)$} & \multicolumn{4}{|c|}{ Temp $\left({ }^{\circ} \mathrm{C}\right)$} \\
\hline & & 28 & 31 & 34 & 37 & 28 & 31 & 34 & 37 \\
\hline Ace-55 UF & --- & 0 & 0 & 0 & 0 & 0 & 0 & 0 & 0 \\
\hline Rutgers & --- & 0 & 0 & 0 & 0 & 0 & 0 & 0 & 0 \\
\hline Better Boy & Mimi & 100 & 100 & 71 & 21 & 100 & 91 & $85^{* *}$ & 12 \\
\hline Celebrity & Mimi & 100 & 100 & 71 & 40 & 100 & 100 & $97^{* * * *}$ & 19 \\
\hline Pik-Red $F_{1}$ & Mimi & 100 & 100 & $32^{*}$ & 30 & 100 & 100 & $3^{*}$ & 20 \\
\hline Pik-Rite $\mathrm{F}_{1}$ & Mimi & 100 & 100 & 61 & 30 & 100 & 100 & 62 & 9 \\
\hline $\mathrm{CLN}^{\mathrm{y}}$ & $M i M i$ & 100 & 100 & $32^{*}$ & 39 & 100 & 100 & 61 & 0 \\
\hline Orion & $M i M i$ & 100 & 100 & 73 & 20 & 100 & 100 & 29 & 0 \\
\hline
\end{tabular}

${ }^{2}$ Percentage of five petri plates.

yAccession CLN 475-BC $\mathrm{B}_{1} \mathrm{~F}_{2}-265-4-19$.

********Significant difference between heterozygous and homozygous genotypes for the $M i$ gene at $P \leq 0.05$, 0.01 , and 0.001 , respectively. 
Cap, G.B., P.A. Roberts, and I.J. Thomason. 1993. Inheritance of heat-stable resistance to Meloidogyne incognita in Lypersicon peruvianum and its relationship to the $M i$ gene. Theor. Appl. Genet. 85:777-783.

Cap, G.B., P.A. Roberts, I.J. Thomason, and T. Murashige. 1991. Embryo culture of Lypersicon esculentum $\times$ L. peruvianum hybrid genotypes possessing heat-stable resistance to Meloidogyne incognita. J. Amer. Soc. Hort. Sci. 116:10821088.

Dropkin, V.H. 1969. The necrotic reaction of tomatoes and other hosts resistant to Meliodogyne: Reversal by temperature. Phytopathology 59:1632-1637.

Dropkin, V.H. 1976. Plant response to root-knot nematodes at the cellular level, p. 43-56. In: J.N Sasser (ed.). Proc. Res. Planning Conf. Rootknot Nematodes, Meloidogyne spp. North Carolina State Univ., Raleigh, 12-16 Jan. 1976.

Eisenback, J.D. and H.H. Triantaphyllou. 1991. Root-knot nematodes: Meloidogyne species and races, p. 191-274. In: W.R. Nickle (ed.). Manua of agricultural nematology. Marcel Dekker, New York.
Ferris, H. and S.D. Van Gundy. 1979. Meloidogyne ecology and host interrelationships, p. 205-230. In: F. Lamberti and C.E. Taylor (eds.). Rootknot nematodes (Meloidogyne species) systematics, biology and control. Academic, New York.

Haroon, S.A., A. Abdul-Baki, and R.N. Huettel. 1993. An in vitro test for temperature sensitivity and resistance to Meloidogyne incognita in tomato. J. Nematol. 25:83-88.

Ho, J.Y., R. Weide, H.M. Ma, M.F. van Wordragen, K.N. Lambert, M.Koornneef, P.Zabel, and V.M. Williamson. 1992. The root-knot nematode resistance gene $(\mathrm{Mi})$ in tomato: Construction of a molecular linkage map and identification of dominant cDNA markers in resistant genotypes. Plant J. 2:971-982.

Lamberti, F. 1979. Economic importance of Meloidogyne spp. in subtropical and Mediterranean climates, p. 341-357. In: F. Lamberti and C.E. Taylor (eds.). Root-knot nematodes (Meloidogyne species): Systematics, biology, and control. Academic, New York.

Laterrot, H. 1973. Selection de varietes de tomate resistantes aux Meloidogyne. European Organization of Plant Protection Bul. 3:89-92.
Mai, W.F. 1985. Plant parasitic nematodes. Their threat to agriculture, p. 11-17. In: J.N. Sasser and C.C. Carter (eds.). An advanced treatise on Meloidogyne. vol. I. Biology and control. North Carolina State Univ. Graphics, Raleigh.

Medina Filho, H.P. and M.A. Stevens. 1980. Tomato breeding for nematode resistance: Survey of resistant varieties for horticultural characteristics and genotype of acid phosphates. Acta Hort. 100:383-393.

Papadopolous, A.P. and H. Tiessen. 1983. Root and air temperature effects on the flowering and yielding of tomato. J. Amer. Soc. Hort. Sci. 108:805-809.

Sasser, J.N. 1977. Worldwide dissemination and importance of the root-knot nematode, Meloidogyne spp. J. Nematol. 9:26-29.

Smith, P.G. 1944. Embryo culture of a tomato species hybrid. Proc. Amer. Soc. Hort. Sci. 44:413-416.

Tindall, J.A., H.A. Mills, and D.E. Radcliffe. 1990. The effect of root zone temperature on nutrient uptake of tomato. J. Plant Nutr. 13:939-956. 